\title{
The gastrointestinal tract, an infrequent target for Waldenström's macroglobulinemia
}

Waldenström's macroglobulinemia is a rare hematological neoplasm that infrequently involves the gastrointestinal tract.

We report a case of a 53-year-old female patient, who was admitted for severe iron-deficiency anemia without evidence of blood loss. Colonic evaluation was normal and esophagogastroduodenoscopy revealed a brown-colored second portion of duodenum with the classic pale appearance of the tip of the folds ( $\bullet$ Fig. 1).

Intestinal biopsies revealed distorted microvilli and isolated acellular, homogeneous eosinophilic deposits, positive for periodic acid-Schiff stain (PAS+), in the lymphatic vessels ( $\bullet$ Fig. 2).

Parasitic causes, celiac disease, and amyloidosis were ruled out. On the basis of the above findings, a bone marrow biopsy was done, which was consistent with large B-cell diffuse lymphoma. Hypergammaglobulinemia with an IgM monoclonal band and elevated lactate dehydrogenase (LDH) were also present. The patient was diagnosed as having lymphoplasmacytoid lymphoma/Waldenström's macroglobulinemia with lymphatic transformation to large B-cell diffuse lymphoma in the bone marrow. Thoracic, abdominal, and pelvic computed tomography (CT) scans and positron emission tomography (PET) revealed no abnormal findings. Six cycles of chemotherapy and intrathecal prophylaxis were successfully tolerated. Complete remission was supported by lack of abnormal findings on esophagogastroduodenoscopy ( $\bullet$ Fig. 3) and a duodenal biopsy ( $\bullet$ Fig. 4 ), and in the bone marrow.

Waldenström's macroglobulinemia is more prevalent in males and in white and elderly people. Clinical features are related to tumor infiltration, hyperviscosity, cryoglobulinemia, and amyloidosis, which are due to the specific properties of monoclonal IgM. Affected organs include the nervous system, bones, kidneys, lungs, liver, spleen, and skin. The small intestine is the most commonly affected segment of the gastrointestinal tract [1 $3]$; only few cases of gastric compromise have been described [4]. Diarrhea, intestinal pseudo-obstruction, protein-losing enteropathy, and overt or occult bleeding
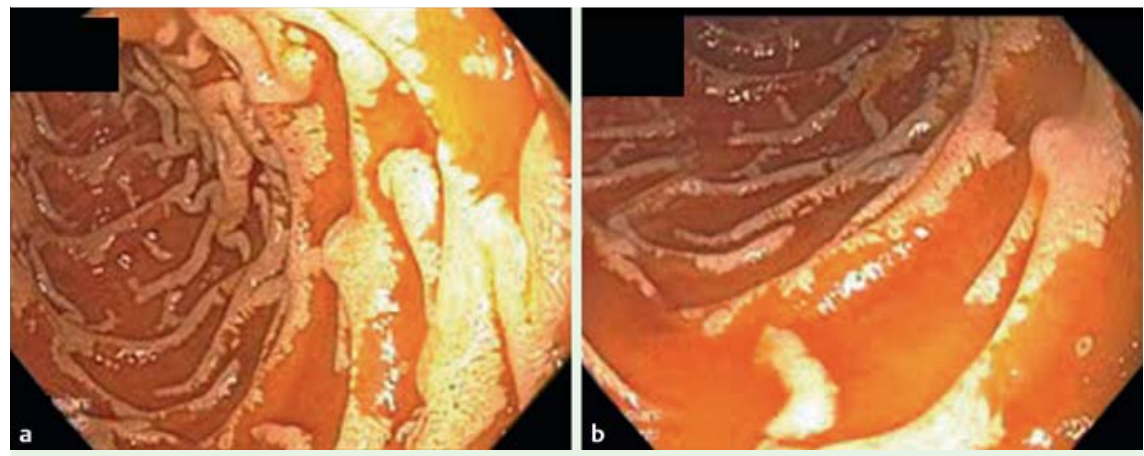

Fig. 1 a, b The characteristic endoscopic images of the duodenum in Waldenström's macroglobulinemia.

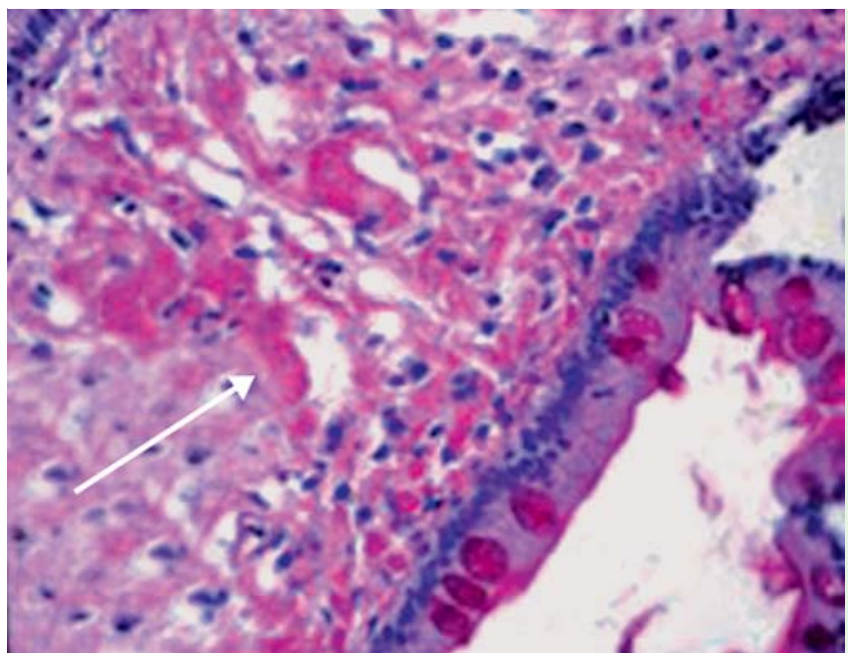

Fig. 2 Histological appearance of the duodenum with eosinophilic deposits (arrow).
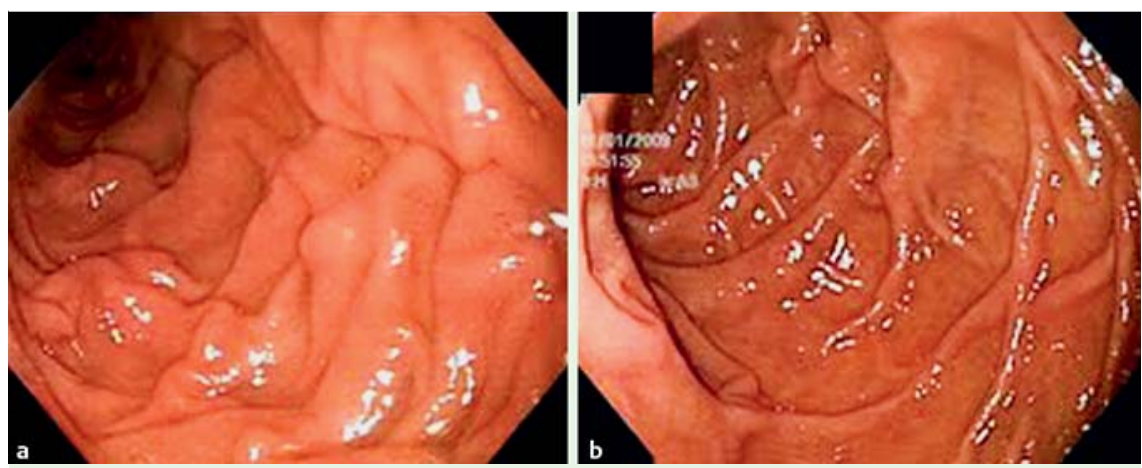

Fig. 3 a, b Normal endoscopic image of duodenum after treatment.

[5] are features indicative of gastrointestinal involvement.

In summary, we present a case with unusual gastrointestinal involvement of a rare hematological malignancy and a lack of specific gastrointestinal symptoms, which was diagnosed following suspi- cious duodenal biopsy findings and improved markedly after treatment.

\section{Competing interests: None}

Endoscopy_UCTN_Code_CCL_1AB_2AZ_3AZ 


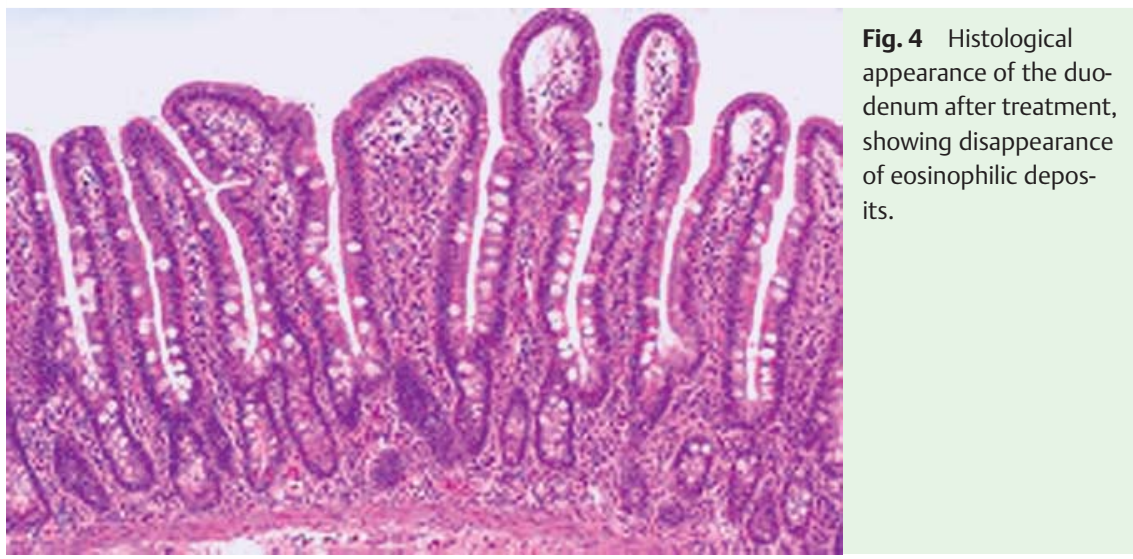

P. C. Rodríguez ${ }^{1}$, C. Sánchez ${ }^{1}$,

M. C. Bolino ${ }^{1}$, L. Caro' ${ }^{1}$ C. Cerisoli ${ }^{1}$,

D. Miserendino², B. Elsner², H. Ferro ${ }^{3}$,

A. Vijnovich ${ }^{4}$

1 Gastroenterologia Diagnostica y

Terapeutica - Endoscopy, Buenos Aires, Argentina

2 Centro de Patología Dr. Elsner Pathology, Buenos Aires, Argentina

3 Swiss Medical Group - Hemathology, Buenos Aires, Argentina
${ }^{4}$ Centro de Citología y Patología CEPACIT - Pathology, Buenos Aires, Argentina

\section{References}

1 Veloso FT, Fraga J, Saleiro JV. Macroglobulinemia and small intestinal disease - a casereport with review of the literature. J Clin Gastroenterol 1988; 10: 546-550

2 Bradley J, Hawkins CF, Rowe DS et al. Macroglobulinaemia and steatorrhoea. Gut 1968; 9: $564-568$
3 Rusynyk RA, Ghosh MS, Babameto GP et al. Endoscopic diagnosis of Waldenström's macroglobulinemia masquerading as chronic diarrhea. Gastrointest Endosc 2003; 57: $800-801$

4 Kaila VL, ElNewihi HM, Dreiling B et al. Waldenström's macroglobulinemia of the stomach presenting as massive upper GI hemorrhage. Gastrointest Endosc 1995; 41: 366

5 Bedine MS, Yardley JH, Elliott HL et al. Intestinal involvement in Waldenström's macroglobulinemia. Gastroenterology 1973; 65: $308-315$

Bibliography

DOI $10.1055 / \mathrm{s}-0029-1244089$

Endoscopy 2010; 42: E129-E130

(c) Georg Thieme Verlag KG Stuttgart · New York . ISSN 0013-726X

Corresponding author

M. C. Bolino

Gastroenterologia Diagnostica

y Terapeutica - Endoscopy

Beruti 2347

PB 'A' C1117AAA

CABA

Buenos Aires

Argentina

Fax: +1-905-5223454

carolinabolino@gedyt.com.ar 